\title{
Comparative Evaluation of Microleakage, Surface Roughness and Hardness of Three Glass Ionomer Cements - Zirconomer, Fujii IX Extra GC and Ketac Molar: An In Vitro Study
}

\section{Shameera Asafarlal*}

Department of Conservative Dentistry \& Endodontics Yenepoya Dental College, Deralakatte Mangalore, 575018 Karnataka, India

"Corresponding author: Shameera Asafarlal, Department of Conservative Dentistry \& Endodontics Yenepoya Dental College, Deralakatte Mangalore, 575018 Karnataka, India, Tel: +91 8971887187; E-mail: drshameerasafarlal@gmail.com

Received date: March 16, 2017; Accepted date: April 5, 2017; Published date: April 11, 2017

Copyright: () 2017 Asafarlal S. This is an open-access article distributed under the terms of the Creative Commons Attribution License, which permits unrestricted use, distribution, and reproduction in any medium, provided the original author and source are credited.

\begin{abstract}
Objective: To compare and evaluate microleakage, surface roughness and hardness of three glass ionomer cements - Zirconomer, Fujii IX Extra GC and Ketac Molar.

Materials and methods: For microleakage evaluation, 150 extracted human maxillary permanent first premolars were randomly divided into five groups of 30 teeth each. Standardized class $V$ cavity preparation was done on the buccal surface of all the groups except group 1. In group 2, cavity was prepared but left unrestored. Group 3, 4 and 5 were restored with Zirconomer, Fujii IX Extra GC and Ketac Molar respectively. Teeth were themocycled together for 500 cycles. All the samples were placed in $0.5 \%$ methylene blue for $24 \mathrm{hrs}$. Volumetric microleakage evaluation was done using spectrophotometer. For each material 15 samples were prepared, of which 10 samples were polished using Sof Lex discs. Samples were processed for surface roughness evaluation, 5 samples from each group before polishing \& 5 samples after polishing. 5 samples from each group were processed for Vicker's hardness test.
\end{abstract}

Results: All the five groups showed some amount of microleakage. Microleakage value of group 2 was greater followed by group 3, group 4, group 1 and group 5 respectively. Ketac Molar showed lower surface roughness value before \& after polishing. Fujii IX Extra GC showed higher hardness followed by Ketac Molar and Zirconomer.

Conclusion: No material was able to completely eliminate microleakage at cervical margin. Ketac Molar showed lower surface roughness before and after polishing. Fujii IX Extra GC showed high hardness among the materials tested.

Keywords: Glass ionomer cement; Class V cavity; Microleakage; Surface roughness; Hardness

\section{Introduction}

Class V cavity has complex morphology because cervical margin of class $\mathrm{V}$ cavity is usually located in dentin. Microleakage occurs at this restoration - dentin interface [1]. Microleakage around dental restorations results in postoperative sensitivity, chronic hypersensitivity, secondary caries, and pulpal pathosis [2]. Glass ionomer cements are indicated for dentin class $\mathrm{V}$ cavities because they bond chemically to the tooth structure.

Surface roughness of a restorative material has great influence on its esthetic appearance, wear and longevity of the restorations. A rough surface facilitates plaque accumulation, surface discoloration and gingival inflammation [3]. New GIC formulations are being introduced every day and it is important to know the physical and mechanical properties of each product when selecting GICs as restorative mater.

Hence the purpose of this study was to evaluate microleakage, surface roughness and hardness of three glass ionomer cements namely Zirconomer, Fujii IX extra and Ketac molar.

\section{Method and Materials}

\section{Microleakage evaluation}

One fifty sound extracted human maxillary permanent premolars were selected for this study. Teeth were cleaned with pumice and placed in distilled water at room temperature to prevent dehydration. Teeth were randomly divided into 5 groups of 30 teeth each:

- Group 1- Positive control (sound teeth- receives no cavity preparation).

- Group 2- Negative control (class V cavity prepared but receives no restoration).

- Group 3- Class V cavity restored with Zirconomer (Shofu, Japan).

- Group 4- Class V cavity restored with Fujii IX Extra (GC, America).

- Group 5- Class V cavity restored with Ketac Molar (3M ESPE, USA).

Standardized class V cavity was prepared on the buccal surface of each tooth except group1 using tapered fissure carbide bur (No.271, SSC White, Lakewood, New Jersey) in a high-speed handpiece (air rotor NSK, Japan) with water coolant. One bur was used for only 4 preparations. The dimensions of the cavities were $1.5 \mathrm{~mm}$ depth, 1.5 
Page 2 of 5

$\mathrm{mm}$ width and $1.5 \mathrm{~mm}$ length. A William's graduated periodontal probe (Hu-friedy, Chicago, IL, USA) was used to measure the dimensions of the cavity. The teeth were then placed in distilled water at room temperature.

For group 3, 4 and 5, the cavity walls were conditioned with dentin conditioner for $10 \mathrm{sec}$, washed with distilled water for $30 \mathrm{sec}$ and dried. Cements were mixed according to the manufactures directions and placed into the cavity. Mylar matrix band (Samit Products, Delhi, India) was placed over the restorations. After 7 minutes, matrix band was removed and varnish was applied on the restorations. Teeth were then placed in distilled water for $24 \mathrm{hrs}$ at $37^{\circ} \mathrm{C}$. Finishing of the restorations were done using finishing burs (GIC finishing \& polishing kit, SHOFU) and aluminium oxide disks (Sof-Lex, 3M ESPE, St Paul USA) with water spray. Teeth were then stored in distilled water at room temperature.

\section{Thermocycling and dye penetration}

All restoration surfaces were protected with adhesive tape. Two coats of nail varnishes were applied to the external surfaces of all teeth leaving a $1.5 \mathrm{~mm}$ margin around the restorations. Each group was then placed into separate mesh bags and thermocycled for 500 cycles in water bath between $5^{\circ} \mathrm{C} \pm 2{ }^{\circ} \mathrm{C}$ and $55^{\circ} \mathrm{C} \pm 2^{\circ} \mathrm{C}$ with 30 seconds dwell time in each bath and a 15 second transfer time.

After thermocycling, teeth were individually placed in $1.3 \mathrm{~mL}, 0.5 \%$ methylene blue at $37^{\circ} \mathrm{C}$. After $24 \mathrm{hrs}$ teeth were removed from dye solution and rinsed in running water. The nail varnish was removed with a blade. The restorations were polished with Sof-Lex disks to remove superficial dye.

\section{Microleakage quantification}

Each tooth was individually immersed in tube containing $2 \mathrm{ml} 65 \%$ nitric acid. Standard solutions of methylene blue in $2 \mathrm{~mL}$ of nitric acid were prepared containing from $0,2,4,6,8,10 \mu \mathrm{g}$ dye $/ \mathrm{mL}$. After $48 \mathrm{hrs}$ teeth were completely dissolved in nitric acid solutions. The standard and experimental nitric acid solutions were diluted with $1 \mathrm{ml}$ distilled water. The solutions were centrifuged ( $4000 \mathrm{rpm}$, Cooling centrifuge, REMI) and supernatant was used to determine the absorbance in spectrophotometer (UV 1800, UV Spectrophotometer, SHIMADZU) at $598 \mathrm{~nm}$. Data obtained were statistically analyzed using one way ANOVA with post-hoc test.

To estimate the dye concentration of the experimental solutions, a linear regression was obtained and generically expressed as:

$$
y=a+b x
$$

Where $\mathrm{y}$ is the absorbance and $\mathrm{x}$ is the dye concentration. Marginal leakage was recorded as $\mu \mathrm{g} / \mathrm{mL}$.

\section{Preparation of specimen for evaluation of surface roughness and hardness}

A mould with diameter $8 \mathrm{~mm}$ and depth $2 \mathrm{~mm}$ was prepared to make the samples. The mould was placed on top of a glass plate and a mylar strip. The GICs were mixed and placed into the moulds slightly excessively. A mylar strip and a glass plate was then placed on top of the filled mould. Excess materials were removed with a BP blade.

Group1: Zirconomer ( $\mathrm{n}=15)$

Group2: Fujii IX Extra GC (n=15)
Group3: Ketac Molar (n=15)

\section{Surface roughness evaluation}

5 samples from each group was processed for profilometric (Surtronic $3+$ profilometer -Taylor Hobson limited, England) evaluation in 5 different position before polishing and 5 samples after polishing using a series of Sof Lex discs. Mean surface roughness (Ra) value was then calculated and statistically analysed using paired t test, one way ANOVA and post hoc test.

\section{Hardness evaluation}

5 samples from each group was polished using a series of Sof Lex discs and processed for Vicker's microhardness test (HMV Microhardness Tester, Shimadzu, Japan). A 200 gf load was applied with dwell time of $15 \mathrm{sec}$. Hardness of each sample was measured in 5 positions. Mean Vicker's hardness value was calculated and statistically analyzed using One Way ANOVA with Post hoc test.

\section{Scanning electron microscopic analysis}

One sample (diameter $8 \mathrm{~mm}$ and depth $2 \mathrm{~mm}$ ) from each group was prepared and polished using a series of Sof-Lex disc. All three samples were sputter coated with silver and kept for scanning electron microscopic analysis. Surface topography of all three samples were examined together in scanning electron microscope (ISM-840A, Jeol, Tokyo, Japan).

\section{Statistical Analysis}

For microleakage evaluation, data were analyzed by one way ANOVA and post hoc test. There was significant difference between the groups ( $\mathrm{p}$ value -0.007). With multiple comparisons, the mean difference was significant at 0.05 level. For Surface roughness evaluation, data were analyzed using paired $t$ test and one way ANOVA and post-hoc test. There was significant difference in each group before and after polishing. For Hardness evaluation, data were analyzed by one way ANOVA and post hoc test.

\section{Result}

\section{Microleakage}

Average microleakage value of group 2 was greater followed by group 3, group 1, group 4 and group 5 respectively (Figure 1). When comparing the materials evaluated, microleakage value of Zirconomer was higher than Fujii IX Extra GC \& Ketac Molar.

One way ANOVA showed there were significant difference between groups $(\mathrm{p}<0.05)$ (Table 1). Post hoc test showed there was significant difference between group 2 with group 1 , group 4 and group 5 .

\section{Surface roughness}

Average surface roughness value of group 3 was less than the other two groups. However, group 1 and group 2 showed better surface finish after polishing (Figure 2).

There was significant difference in each group both before and after polishing. However, there was no significant difference between groups after polishing (Table 2). 
Citation: Asafarlal S (2017) Comparative Evaluation of Microleakage, Surface Roughness and Hardness of Three Glass lonomer Cements Zirconomer, Fujii IX Extra GC and Ketac Molar: An In Vitro Study. Dentistry 7: 427. doi:10.4172/2161-1122.1000427

Page 3 of 5

\begin{tabular}{|l|l|l|l|}
\hline Group & Restorative System & Mean & Standard deviation \\
\hline $\mathbf{1}$ & - & 5.7927 & 2.60702 \\
\hline $\mathbf{2}$ & - & 17.9384 & 3.20903 \\
\hline $\mathbf{3}$ & Zirconomer & 9.8787 & 8.08162 \\
\hline $\mathbf{4}$ & Fujii IX Extra & 5.9756 & 3.79423 \\
\hline $\mathbf{5}$ & Ketac Molar & 5.5488 & 3.06823 \\
\hline
\end{tabular}

Table 1: Average microleakage value of five groups tested.

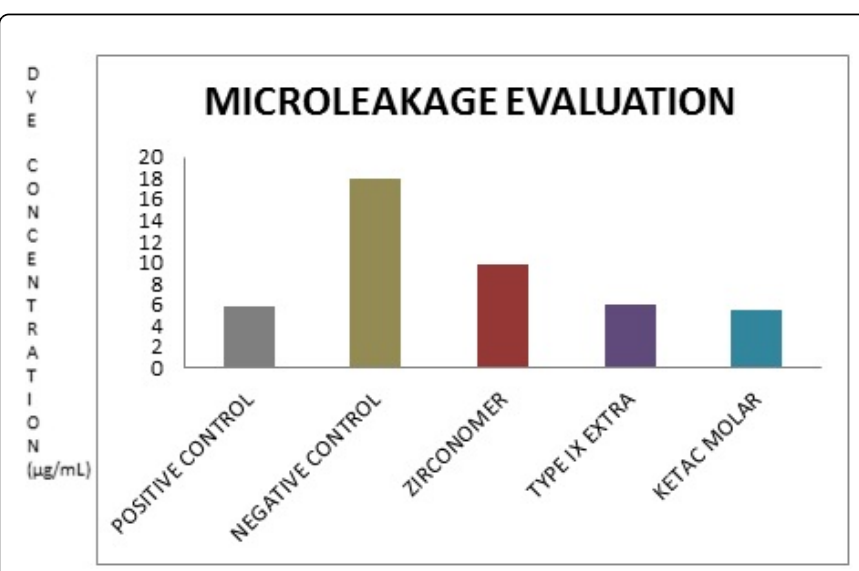

Figure 1: Mean microleakage of tested materials.

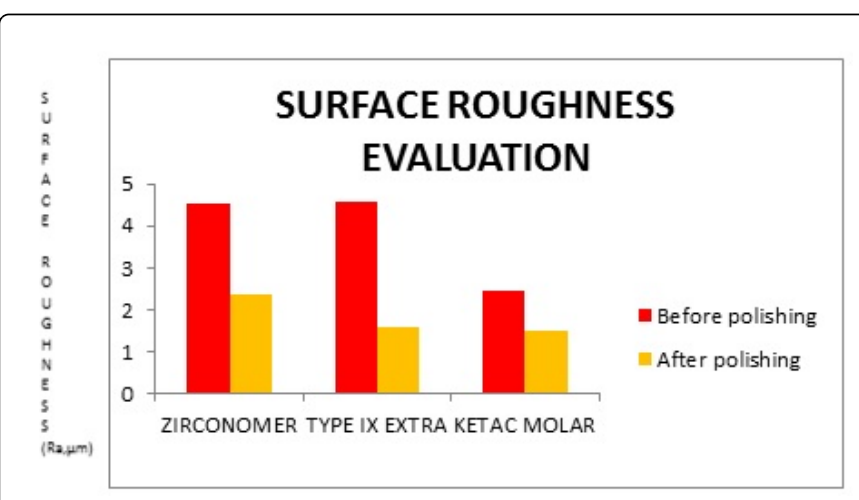

Figure 2: Mean surface rougness of tested materials before \& after polishing.

\begin{tabular}{|l|l|l|l|l|}
\hline \multicolumn{2}{|l|}{} & \multicolumn{2}{l|}{ Before Polishing } & \multicolumn{2}{l|}{ After Polishing } \\
\hline Group & Mean & Standard deviation & Mean & Standard deviation \\
\hline Zirconomer & 4.5104 & 0.28633 & 2.3760 & 0.33810 \\
\hline Fujii IX Extra & 4.5704 & 0.31595 & 1.5924 & 1.09374 \\
\hline Ketac Molar & 2.4640 & 1.14752 & 1.5092 & 0.26124 \\
\hline
\end{tabular}

Table 2: Average surface roughness value of tested materials before and after polishing.

\section{Hardness}

Table 3 summarizes average hardness values of three glass ionomer cements tested. Group 2 showed higher hardness followed by group 3 and group 1 (Figure 3). There were significant differences between three groups.

\begin{tabular}{|l|l|l|}
\hline Group & Mean & Standard Deviation \\
\hline Zirconomer & 54.2080 & 7.06924 \\
\hline Fujii IX Extra & 83.4560 & 4.81415 \\
\hline Ketac Molar & 78.1480 & 10.53217 \\
\hline
\end{tabular}

Table 3: Average hardness value of tested materials.

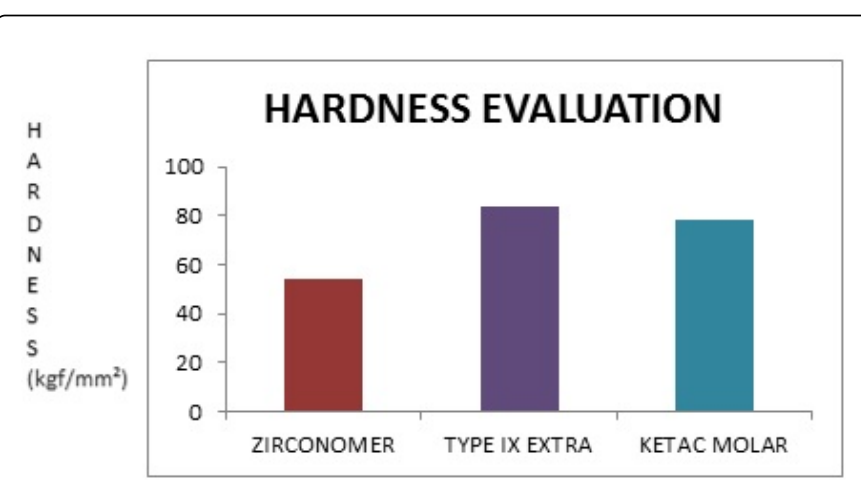

Figure 3: Mean hardness of tested material.

\section{Discussion}

Restoration of cervical lesion is always a challenge because cervical margin of such lesion is in dentin or cementum [4]. Glass ionomer cement is indicated for cervical lesion especially when aesthetic is not a prime concern. The properties of GICs over composite restorative material are it's ability to bond chemically to the tooth structure, release fluoride, biocompatible, lower shrinkage and reduced microleakage [5]. Several methods have been used to detect microleakage. Dye penetration method was used in this study because it is simple, inexpensive, fast [6].

Methylene blue $(0.5 \%)$ was used in this study because of it's low cost, ease of application and low molecular weight of the dye, which is smaller than bacteria [7,8]. Microleakage studies are usually done qualitatively [5,9]. In this study, spectrophotometer was used to assess the dye penetration because it allows volume of dye penetrated rather than two dimensional linear measurements [10]. Teeth were subjected to thermal stresses to simulate the temperature changes that take place in the oral environment [11].

To overcome the shortcomings of GIC, researchers have formulated GICs with improved handling properties, resistance to surface wear and fracture [12]. Zirconomer is a ceramic and zirconia reinforced glass ionomer cement. It exhibits the strength of amalgam and at the same time maintain the fluoride releasing capacity of GICs [13]. Fujii IX Extra GC is the latest addition to the glass ionomers that offer unsurpassed wear resistance, compressive strength, and durability. This product contains glass filler, Smart Glass. Addition of this filler provides higher translucency, reactivity and a faster setting time [14]. 
Citation: Asafarlal S (2017) Comparative Evaluation of Microleakage, Surface Roughness and Hardness of Three Glass lonomer Cements Zirconomer, Fujii IX Extra GC and Ketac Molar: An In Vitro Study. Dentistry 7: 427. doi:10.4172/2161-1122.1000427

Page 4 of 5

Ketac Molar is a viscous glass ionomer and it has been shown to perform well both as a restorative and a sealant. The high powder to liquid ratio in Ketac Molar gives it high compressive strength [15,16].

In this study microleakage of Zirconomer was more than that of Fujii IX Extra GC \& Ketac Molar. One explanation to this is that large size of the filler particle in Zirconomer prevents proper adaptation of this material to the tooth surface. Average microleakage value of Fujii IX extra GC, Ketac Molar and intact teeth were similar. This may be due to better sealing properties of Fujii IX Extra GC and Ketac Molar to the tooth surface.

Polishability is an important property of a restorative material which determines it's longevity, biocompatibility and esthetic appearance [17]. Mylar strip is commonly used to achieve a smooth surface of direct esthetic restoration [18]. Surface finish obtained with the mylar strip is because of it's precontoured transparent matrix system and removing excess restorative material with it's fine blade [19]. However best surface finish for GIC is obtained with aluminiumoxide discs $[18,20]$. So aluminium oxide discs were used in this study to polish GICs. Contact profilometer was used in this study to determine the polishability because it is easy to operate, accurate and versatile [21].

Fujii IX Extra GC showed better shade matching at cervical areas. Zirconomer did not match with the shade of the tooth at the cervical region. Another disadvantage of Zirconomer is that it's poor working consistency, longer setting time, and rough surface texture.
The result obtained in this study showed that surface rougness of Ketac Molar was less compared to Zirconomer and Fujii IX Extra GC. This result is in agreement with previous studies [22]. Zirconomer showed least polishability. This may be due to large filler particle incorporated in the cement. Increase in surface roughness results in alterations in light reflection and material surface turn opaque [23]. Studies showed that material with large particle size possess high surface rougness [24]. Ketac Molar exhibits superior esthetic qualities because of the presence of smaller filler particle size.

The result obtained in this study indicated that hardness of Fujii IX Extra GC was higher than Zirconomer and Ketac Molar. There were significant differences between three groups. But in another study it was showed that a mean hardness value of Ketac Molar was slightly higher than Fujii IX Extra GC [25]. Particle size and matrix differ from one material to the other, thus the hardness. So each material possess different polishability. For effective finishing, the cutting particles must be harder than the filler materials [26]. Method of polishing affects the surface hardness of the GIC because it involves polishing of the glass particles.

The SEM analysis indicated that all three GICs showed voids and cracks on their surfaces (Figure 4). The voids may be incorporated during the sample preparation and cracks during the processing of samples for SEM analysis.

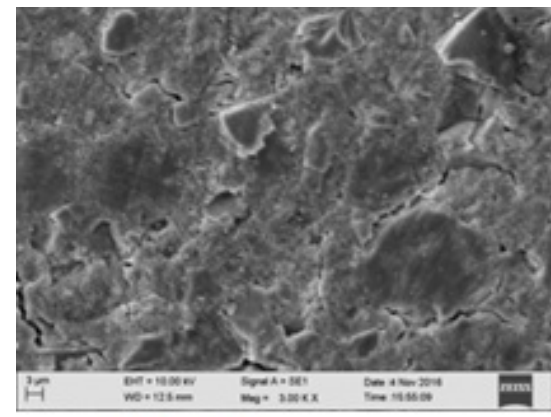

Zirconomer

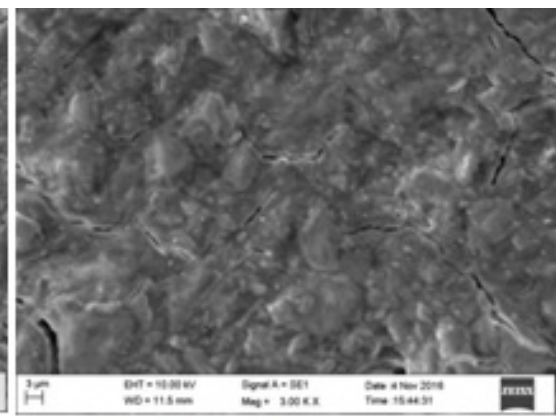

Fujii IXExtra GC

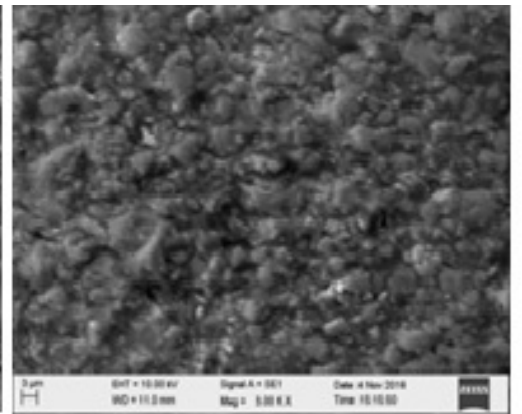

KetacMolar

Figure 4: Surface topography of Zirconomer, Fujii IX Extra \& Ketac Molar under 3.0 kx magnification.

\section{Conclusion}

Sealing property of Zirconomer is lower than that of Ketac Molar \& Fujii IX Extra GC. No material was able to completely eliminate microleakage at cervical margin. Ketac Molar showed best surface finish before and after polishing. Fujii IX Extra GC showed high hardness and excellent shade matching at buccal surface of the cervical third of the tooth.

\section{References}

1. Silveira AC, Incerti ST, Ogliari FA, Meireles SS, Piva E (2006) Microleakage of seven adhesive systems in enamel and dentin. J Contemp Dent Prac 7: 26-33.

2. Going RE (1972) Microleakage around dental restorations: a summarizing review. The Journal of the American Dental Association 30: 1349-1357.
3. Jefferies SR (1998) The art and science of abrasive finishing and polishing in restorative dentistry. Dental Clinics of North America 42: 613-627.

4. Manhart J, GarciaGodoy F, Hickel R (2002) Direct posterior restorations: Clinical results and new developments. Dent Clin North Am 46: 303-339.

5. Yap AU, Lim CC, Neo JC (1995) Marginal sealing ability of three cervical restorative systems. Quintessence International 1: 26.

6. Alani AH, Toh CG (1997) Detection of microleakage around dental restorations: A review. Oper Dent 22: 173-185.

7. JB Almeida, JA Platt, Y Oshida, BK Moore, MA Cochran (2003) Three different methods to evaluate microleakage of packable composites in class II restorations. Op Dent 28: 453-460.

8. Mayank U (2015) Patel, SandhyaKapoorPunia, and Chirag M. Raiyani. An in vitro Evaluation of Microleakage of Posterior Teeth Restored with Amalgam, Composite and Zirconomer - A Stereomicroscopic Study. J Clindiagn Res 9: 65-67.

9. Monteiro S, Sigurjons H, Swartz ML, Phillips RW, Rhodes BF (1986) Evaluation of materials and techniques for restoration of erosion areas. J Prosthet Dent 55: 434-442. 
Citation: Asafarlal S (2017) Comparative Evaluation of Microleakage, Surface Roughness and Hardness of Three Glass lonomer Cements Zirconomer, Fujii IX Extra GC and Ketac Molar: An In Vitro Study. Dentistry 7: 427. doi:10.4172/2161-1122.1000427

Page 5 of 5

10. Douglas WH, Zakariasen KL (1981) Volumetric assessment of apical leakage utilizing a spectrophotometric dye-recovery method abstract 512 J Dent Res 60: 438.

11. Wahab FK, Shaini FJ, Morgano SM (2003) The effect of thermocycling on microleakage of several commercially available composite class V restorations in vitro. J Prosthet Dent 90: 168-174.

12. Alani AH, Toh CG (1997) Detection of microleakage around dental restorations: A review. Oper Dent 22: 173-185.

13. http://www.shofu.com.sg/downloads/pdf/Zirconomer\%20Brochure.pdf.

14. http://www.gcindiadental.com/wpcontent/uploads/brochures/ GC_Fuji_IX_Extra_Brochure.pdf

15. Holmgren CJ, Lo ECM, Hu DY, Wan HC (2000) ART restorations and sealants placed in Chinese school children- results after three years. Community Dent Oral Epidemiol 28: 314-320.

16. Xie D, Brantley WA, Culbertson BM, Wang G (2000) Mechanical properties and microstructures of glass-ionomer cements. Dent Mater 16: 129-138.

17. Yip HK, Lam WTC, Smales RJ (1999) Fluoride release, weight loss and erosive of modern aesthetic restoratives. Br Dent J 197: 265-270.

18. Pedrini D, Candido MS, Rodrigues AL (2003) Analysis of surface roughness of glass-ionomer cements and compomer. Journal of oral rehabilitation 30: 714-719.

19. Puttur LM, Shashirashmi A, Vasudev B, Kishore G, Manuel T (2013) Profilometric study to compare the effectiveness of various finishing and polishing techniques on different restorative glass ionomer cements. Journal of Interdisciplinary Dentistry 3: 2.

20. Tate WH, Powers JM (1996) Surface roughness of composites and hybrid ionomers. Oper Dent 21: 53-58.

21. Koupis NS, Marks LA, Verbeeck RM, Martens LC (2007) Review: Finishing and polishing procedures of (resinmodified) glass ionomers and compomers in paediatric dentistry. Eur Arch Paediatr Dent 8: 22-28.

22. Pitkethy M (2003) Nanoparticles as building blocks. Materials Today 6: 36-42.

23. Prabhakar AR, Priyanka LK, Chandrashekar Y, Sugandhan S (2003) Assessment of the clinical performance of zirconia infused glass ionomer cement: An in vivo study 30: 209.

24. Gladys S, Van MB, Braem M, Lambrechts P, Vanherle G (1997) Comparative pysico-mechanical characterization of new hybrid restorative materials with conventional glass-ionomer and resin composite restorative materials. J Dent Res 76: 883-894.

25. Peutzfeldt A, Garcia-Godoy F, Asmussen E (1997) Surface hardness and wear of glass ionomers and compomers. Am J Dent 10: 15-17.

26. Wilder AD, Swift EJ, May KN, Thompson JY, McDougal RA (2000) Effect of finishing technique on the microleakage and surface texture of resinmodified glass ionomer restorative materials. Journal of Dentistry 28: 367-73. 